\title{
Soroprevalência da infecção chagásica em moradores de municípios da região de Botucatu, Estado de São Paulo
}

\author{
Seroprevalence of Chagas infection among inhabitants \\ of municipalities in the Botucatu region, State of São Paulo
}

Ilda de Godoy e Domingos Alves Meira²

\begin{abstract}
RESUMO
O objetivo deste estudo foi o de procurar evidências da transmissão vetorial da doença de Chagas, nos domicílios e peridomicílios de indivíduos residentes em municípios da região de Botucatu, que tiveram xenodiagnóstico positivos. Foram estudados 58 indivíduos e foi coletada amostra do sangue para a realização de exames laboratoriais. Os resultados deste estudo mostraram que os indivíduos, de ambos os grupos, tinham baixa escolaridade e exerciam profissões que não exigiam qualificações técnicas. Houve discreto predomínio de indivíduos do sexo feminino. Quando comparadas às condições anteriores, verificou-se que houve discreta melhora nas condições de habitação, por outro lado, houve aumento de moradores em zona rural. Os indivíduos nascidos antes de 1983, apresentaram conhecimento e contato com triatomídeo estaticamente mais elevado quando comparado com os nascidos a partir 1983. A análise e comparação dos resultados das sorologias, referentes aos hemaglutinação passiva indireta, imunofluorescência indireta e ensaio imunoenzimático, mostrou que o ELISA apresentou maior sensibilidade. Os resultados deste estudo mostram que a população nascida a partir de 1983 não conbecia o vetor transmissor da doença de Chagas.
\end{abstract}

Palavras-chaves: Doenças de Chagas. Infecção chagásica. Transmissão vetorial.

\section{ABSTRACT}

The aim of this study was to look for evidence of vector transmission of Chagas disease, in and around the homes of individuals living in municipalities in the Botucatu region who presented a positive xenodiagnosis. Fifty-eight subjects were studied and blood samples were collected from them for laboratory analysis. The results from this study showed that the individuals in both groups presented low formal education levels and had been working in unskilled professions There was a slight predominance of females. In comparison with previous conditions, it was observed that there had been a slight improvement in the subjects' housing conditions, but on the other hand there had been an increase in the numbers of individuals living in rural areas. Subjects born before 1983 presented statistically greater knowledge of and contact with triatomines than did those born from 1983 onwards. Analysis and comparison of the results from the serological tests, including indirect passive bemagglutination, indirect immunofluorescence and immunoenzymatic assay, showed that ELISA presented greatest sensitivity. The results from this study have shown that the population born from 1983 onwards did not know about the transmission vector for Chagas disease.

Key-words: Chagas disease. Chagas infection. Vector transmission.

A doença de Chagas, descrita em 1909 por Carlos Chagas, é enfermidade infecciosa causada por protozoário flagelado da espécie Trypanosoma cruzi ${ }^{42}$. A transmissão natural se faz pela contaminação da pele ou mucosas pelas fezes dos vetores insetos hematófogos estritos, da família Triatominae, conhecidos genericamente por triatomíneos contendo formas infectantes de Trypanosoma cruzi. Os mecanismos secundários de transmissão são por via transfusional, materno-infantil (transplacentária ou por aleitamento materno), via oral, transplante de órgãos e a transmissão acidental, mais freqüente pela manipulação de material contaminado em laboratório. Entre estas possibilidades de veiculação do triatomíneo, vetor da infecção, tem especial importância epidemiológica a transmissão por transfusão de sangue, que pode fazer com que a doença se dissemine para áreas sem transmissão natural, inclusive para grandes centros populacionais. Outro, é a transmissão congênita, que pode representar risco mais duradouro de produção de novos casos e de manutenção da endemia chagásica ${ }^{425} 2627$.

\footnotetext{
1. Departamento de Enfermagem, Faculdade de Medicina de Botucatu, Universidade Estadual Paulista, Botucatu, SP. 2. do Departamento de Doenças Tropicais e Diagnóstico por Imagem, Faculdade de Medicina de Botucatu, Universidade Estadula Paulista, Botucatu, SP.

Endereço para correspondência: Profa Ilda de Godoy. Dept ${ }^{\circ}$ de Enfermagem/FMB/UNESP. Rubião Júnior s/n, Campus de Botucatu, 18618-000 Botucatu, SP

Tel: $55143811-6004$

e-mail: degodoy@fmb.unesp.br

Recebido para publicação em: 8/02/2007

Aceito em: 17/08/2007
} 
Estudos de custo-benefício ou custo-efetividade têm mostrado que o controle das condições que facilitam a infecção é muito mais efetivo que os gastos com atenção ao paciente chagásico ${ }^{51923}$.

Apesar da magnitude do problema representado pela doença de Chagas e de se dispor de tecnologia comprovadamente eficaz, isso não foi bastante para manter ação regular de controle da doença. Entre 1950 e 1975, apenas atividades pontuais e discontínuas foram cumpridas e muitos indivíduos, certamente, foram infectados nesse período e contribuem para o número de chagásicos crônicos até hoje. A partir de 1975, com os avanços obtidos no controle da malária e com os recursos daí excedentes, o controle da doença de Chagas no país passou a ter maior prioridade ${ }^{24}$.

Entre 1975 e 1983, foram realizados os primeiros inquéritos entomológicos e sorológicos, em todo o país. Desta forma foram conhecidas as áreas endêmicas da doença e também definidas e priorizadas as ações de controle. Em 1983, a área endêmica reconhecida correspondia a $36 \%$ do território nacional. Na época, a prevalência da infecção no meio rural foi de 4,2\%, excluído o estado de São Paulo, onde a transmissão estava virtualmente interrompida ${ }^{24}$.

No período de 1990 a 1998, foram pesquisadas, dentro das atividades de rotina do Programa de Controle da Doença de Chagas no Estado de São Paulo, 127.408 unidades domiciliares. No mesmo período, constatou-se a ocorrência isolada e dispersa de apenas três exemplares do Triatoma infestans. Todos foram notificados por moradores da região de Campinas, nenhum deles infectado por Trypanosoma cruzi. Somente o atendimento à notificação de um exemplar do triatomíneo, proveniente da área rural do município de Paulínia, resultou no encontro de uma colônia e captura de 109 exemplares do Triatoma infestans ${ }^{924}$. 0 encontro deste último foco, após uma década sem registro de infestação importante por Triatoma infestans no Estado de São Paulo, foi motivo de preocupação das autoridades da área de Saúde Pública ${ }^{14}$.

Tendo em vista a inexistência de registro de transmissão vetorial a partir de 1983, pressupõe-se que os indivíduos infectados pelo Trypanosoma cruzi e que vivem no Estado de São Paulo tenham adquirido a infecção antes de 1983. Muitos indivíduos que têm a infecção chagásica transferiram-se do meio rural para o urbano e, como tal, alguns deles tornaram-se doadores de sangue voluntários ou de reposição, no caso da região de Botucatu, do Hemocentro da Faculdade de Medicina de Botucatu da Universidade Estadual Paulista. Houve, então, interesse em saber se, no domicílio e peridomicílio dos indivíduos com xenodiagnóstico positivo, haveria evidências de transmissão vetorial do Trypanosoma cruzi, em habitantes residentes na região de Botucatu, nascidos a partir de 1983.

\section{PACIENTES E MÉTODOS}

A pesquisa foi desenvolvida na região de Botucatu no período de agosto a outubro de 2002. A casuística foi constituída pelos contatos dos pacientes que apresentaram, a partir do ano de 1997, diagnóstico parasitológico da doença de Chagas por xenodiagnóstico artificial positivo, e que estavam em acompanhamento no Ambulatório de Doenças Tropicais da Faculdade de Medicina de Botucatu da Universidade Estadual Paulista.

Todos os indivíduos visitados aceitaram fazer parte do estudo. Assim, foram estudados 58 indivíduos que foram alocados em dois grupos de acordo com o ano de nascimento: Grupo 1 (G1): 29 indivíduos nascidos a partir de 1983, 20 do sexo feminino e 9 do masculino, com idades na faixa etária de 3 a 19 anos. Grupo 2 (G2): 29 indivíduos nascidos antes de 1983, 16 do sexo feminino e 13 masculino, na faixa etária de 20 a 68 anos.

Trata-se de pesquisa qualitativa e de epidemiologia clínica. Uma ficha de entrevista pré-testada padrão foi utilizada para coleta de dados dos participantes do estudo, no momento da visita domiciliar que, entre outras informações, continha os antecedentes epidemiológicos pessoais e familiares. Em seguida, foi coletada amostra de sangue de todos os indivíduos, para realização de provas sorológicas. Nos testes sorológicos para a pesquisa de anticorpos antiTrypanosoma cruzi, foram utilizados os métodos de hemaglutinação passiva indireta (HAI), imunofluorescência indireta (IFI) e ensaio imunoenzimático (ELISA).

$\mathrm{Na}$ tentativa de elucidação de eventuais casos, nos quais os testes sorológicos foram inconclusivos, foram considerados outros procedimentos clínico-laboratoriais como à observação clínica e adicionalmente: hemocultura em meio de Liver Infusion Tryptose (LIT), reação em cadeia pela polimerase (PCR) e xenodiagnóstico artificial.

Foi realizada análise descritiva dos resultados e para comparação entre e intra grupos de estudo foi utilizado o teste do $\chi_{1}^{2}$, as estatísticas foram consideradas significativas quando $\mathrm{p}<0,05$. Nos casos em que a variável era igual a zero, foi realizada a correção de Yates ${ }^{28}$.

0 presente estudo recebeu parecer favorável, aprovado em reunião de 04/02/2002/ 0F.006/2002-CEP/MJBV/asc, do Comitê de Ética em Pesquisa da Faculdade de Medicina de Botucatu da Universidade Estadual Paulista.

\section{RESULTADOS}

Na comparação entre os dois grupos de estudo, não ocorreu diferença estatística em relação ao sexo, apenas houve discreta diferença numérica e percentual de indivíduos do sexo feminino, em G1 e G2, 20 (69\%) e 16 (55,2\%) respectivamente. Quanto à faixa etária, embora tenha havido diferença na comparação entre os grupos, a mesma não deve ser considerada, pois a faixa etária foi um dos critérios de classificação nos grupos de estudo.

As escolaridades predominantes em G1, foram analfabetos 18 (75\%), alfabetizado um (4,2\%) e o ensino fundamental cinco (20,8\%). Enquanto no G2, as escolaridades predominantes foram: analfabetos oito (27,6\%) e alfabetizados 15 (51,7\%).

Nas ocupações informadas pelos indivíduos participantes, observa-se que em G1 houve predomínio de estudantes 18 (75\%), e em G2, a classificação do lar 15 (51,7\%) foi a que mais se destacou. 
Nos dois grupos, a maioria $(93,1 \%)$ dos indivíduos nasceu no Estado de São Paulo, enquanto quatro (6,9\%) eram naturais do estado do Paraná e que a maior (44,8\%) proporção deles era procedente do município de Taquarituba.

Na comparação entre $o$ tipo de habitação na infância e atualmente, em G1 houve discreta diferença em números absolutos e relativos, $12(41,4 \%)$ deles habitaram em residências de não alvenaria na infância, enquanto que atualmente $10(34,5 \%)$ deles moram em residência desse tipo. Em G2, também, ocorreu discreta diminuição em números absolutos e relativos, pois $17(58,6 \%)$ deles habitaram em residências que não eram de alvenaria na infância, comparando com 11 (37,9\%) deles atualmente. Entretanto, o estudo estatístico revelou que as diferenças não foram significantes.

Na comparação entre os grupos de estudo, G1 e G2, ocorreu diferença em números absolutos e relativos dos participantes moradores na zona urbana durante a infância 16 (55,2\%) e atualmente $21(72,4 \%)$ e dos moradores na zona rural, 13 (44,8\%) na infância e $8(27,6 \%)$ atualmente. Entretanto, não houve diferença estatística.

Em G1, quanto à presença de doença de Chagas, ou de outras doenças do pai, relatada no dia da entrevista dos 16 pais doentes, sete $(43,7 \%)$ tinham doença de Chagas, enquanto no G2, de seis pais, dois (33,3\%) tinham doença de Chagas. Não ocorreu diferença estatística entre os grupos de estudo. Com relação à mãe, não houve diferença estatística na comparação entre os grupos.

Na distribuição dos indivíduos incluídos nos grupos de estudo, de acordo com o relato de conhecimento e/ou contato com o triatomíneo, nota-se que houve predomínio dos que tiveram contato em G2 (16) 55,2\%, enquanto em G1 somente um (3,5\%) teve contato. Na comparação entre os grupos ocorreu diferença estatística. $\left(\chi_{1}^{2}=18,72, \mathrm{p}<0,001, \mathrm{G} 1<\mathrm{G} 2\right)$.

No relato de transfusão de sangue ou não, nota-se que 28 (96,5\%) dos indivíduos em G1 e 24 (82,8\%) em G2, não receberam transfusão de sangue. Não houve diferença estatística na comparação entre os grupos de estudo para este parâmetro. Entretanto, houve uma tendência segundo a qual ocorreram mais transfusões de sangue nos indivíduos de G2 $\left(\chi_{1}^{2}=2,974, \mathrm{p}<0,10\right.$, Tendência: G1<G2).

Distribuição da casuística de acordo com os resultados dos exames sorológicos. Nos resultados dos testes de HAI observa-se que quatro $(13,8 \%$ ) dos indivíduos do G2 apresentaram resultados reagentes, enquanto que todos de G1 foram não reagentes. Não houve diferença estatística na comparação entre os grupos. Com relação aos resultados dos testes de IFI para diagnóstico da doença de Chagas nota-se que somente cinco $(17,2 \%)$ indivíduos em G2 tiveram resultados reagentes, enquanto todos foram não reagentes em G1. Não ocorrendo diferença estatística na comparação entre os dois grupos de estudo.

No resultado dos testes de ELISA para diagnóstico da doença de Chagas, notou-se que sete $(24,1 \%)$ indivíduos do G2 obtiveram resultados reagentes, enquanto nenhum dos de G1 apresentou reatividade a esse teste. Houve diferença estatística entre os grupos $\left(\chi_{1}^{2}=5,747, \mathrm{p}<0,05, \mathrm{G} 1<\mathrm{G} 2\right.$ com correção de Yates $)$.
Caracterização dos indivíduos com resultados dos exames sorológicos positivos. Todos eram naturais da região de Botucatu, residentes em moradia do tipo não alvenaria, localizadas na zona rural, durante a infância. Atualmente, quatro continuam morando no mesmo tipo de residência e na zona rural. Quatro deles eram do sexo feminino e três do masculino, com idade variando entre 38 e 68 anos; 57,1\% eram alfabetizados e $42,9 \%$ possuem o ensino fundamental. Cinco $(71,4 \%)$ deles conheciam ou tiveram contato com barbeiro e quatro relataram ter recebido transfusão de sangue, e somente um deles tinha antecedente de doença de Chagas (pai).

Busca de triatomíneos em domicílios e anexos. 0 resultado das vistorias realizadas durante 0 dia para detectar presença do vetor no interior da casa e exterior do domicílio foi negativo para a presença do triatomíneos.

Relato de caso especial de G1. Uma das crianças incluídas em G1 apresentou o teste de HAI inconclusivo. Uma menina de oito anos de idade, natural e procedente de Taquarituba, município da região de Botucatu, residente em casa de madeira, na zona rural, e que, segundo relatos da mãe, não teve contato com o barbeiro (triatomíneo). A mãe dessa criança era uma das pacientes em acompanhamento no Ambulatório de Doenças Tropicais da Faculdade de Medicina de Botucatu/UNESP que, no ano de 1998, realizou, no Laboratório de Pesquisa de Doenças Tropicais da Faculdade de Medicina de Botucatu/UNESP, xenodiagnóstico artificial com resultado positivo. Assim, foi umas das pacientes selecionadas para visita domiciliar e peridomiciliar para avaliação das outras pessoas que lá residiam. Após a realização dos primeiros exames sorológicos, para o diagnóstico da doença de Chagas, ELISA, HAI e IFI, colhidos para o estudo, detectou-se HAI com resultado inconclusivo para o diagnóstico da doença de Chagas. Portanto, tomou-se por conduta encaminhá-la para o Ambulatório de Imunologia Especial, Área de Pediatria. Após exame físico detalhado, o médico decidiu realizar nova coleta de sangue e repetir todos os exames sorológicos, afora, também hemocultura, PCR, xenodiagnóstico, radiografia de tórax e eletrocardiograma. Frente à anamnese e exame físico normais sem sinais de anormalidades e os resultados negativos dos novos exames, concluiu-se que a criança não era portadora da doença de Chagas.

\section{DISCUSSÃO}

Entre aquelas transmitidas por vetores, a doença de Chagas é considerada uma das mais importantes como problema de saúde pública, ou por sua elevada prevalência e extensa distribuição geográfica, em algumas regiões do país, ou seja pela letalidade das formas clínicas da doença ${ }^{421}$ Uma das possibilidade de evitar 0 aparecimento das formas clínicas debilitantes e letais da doença de Chagas reside no controle da transmissão vetorial, ou transmissão por transfusão de sangue e transplante de órgãos sólidos, de medula e tecidos ${ }^{13}$.

No período de 1975 a 1983, foi evidente o impacto ocorrido sobre a transmissão vetorial da doença de Chagas, em decorrência das ações de controle baseadas no tratamento 
químico domiciliar ${ }^{25}$. No Estado de São Paulo, no final do ano de 1983, após uma avaliação por uma Comissão Interna de Técnicos da Superintendência de Controle de Endemias, encerrou-se a atividade de aplicação de inquéritos sorológicos em alunos da primeira série do primeiro grau de escolas da zona rural e passou a utilizar a sorologia aplicada a moradores de unidades domiciliares, notificantes de triatomíneos, ou daquelas em que a detecção de vetores decorreu de atividades de busca de rotina ${ }^{2226}$. Portanto, embora a campanha contra o Triatoma infestans no Estado de São Paulo possa ser considerada bem sucedida, é fundamental manter a vigilância epidemiológica e dispor de recursos suficientes para isso $0^{926}$.

Neste estudo, os indivíduos foram classificados em grupos de acordo com a data de nascimento, os nascidos até 1982 e os nascidos após esta data, em razão de o ano de 1983 ter sido um marco importante na história do controle da doença de Chagas no país, quando se conheceu a totalidade da área com vetores domiciliados e quando o controle vetorial foi exercido em caráter pleno $^{24}$.

A análise dos resultados mostrou não ter havido diferença estatística com relação ao sexo na comparação entre os grupos. Poucos estudos relatam o sexo como uma variável que interfira no comportamento da transmissão vetorial da doença de Chagas, dada à eqüiprobabilidade de aquisição da infecção, para ambos os sexos no ambiente domiciliar ${ }^{217}$.

A ausência de soropositivo em grupos de faixa etária menor pode indicar a efetividade da campanha de controle da doença de Chagas ${ }^{1}$.

Quando analisamos a escolaridade dos indivíduos que participaram deste estudo, excluindo-se os menores de sete anos, observou-se que a maioria tinha sua instrução até o ensino fundamental, mostrando que os participantes do estudo tinham baixa escolaridade e exerciam ocupações com atividades que não exigiam qualificação técnica, nesta pesquisa estão as de lavrador entres os homens e do lar entre as mulheres. Em pesquisas sobre os aspectos clínicos, e sociais e trabalhistas da doença de Chagas os resultados associam o portador de doença de Chagas aos estratos mais primários da produção ${ }^{3612}$.

Quanto à naturalidade, a maioria dos indivíduos participantes do estudo era natural do interior do Estado de São Paulo, municípios da região de Botucatu ou de outras regiões próximas. 0 restante era natural do interior do Estado do Paraná, região, que já foi endêmica para doença de Chagas ${ }^{42}$. A maioria dos indivíduos participantes do estudo era procedente do município de Taquarituba, localizado no sudoeste do Estado de São Paulo, que integrou, em passado recente, importante área endêmica da doença de Chagas. Aí predominava, como na maior parte do Estado, o vetor Triatoma infestans ${ }^{15}$.

Estudos relacionam a doença de Chagas a condições de habitação, em geral de barro, madeira, sapé, com pouca higiene, situada na zona rural, situações essas que favorecem a permanência do vetor ${ }^{42}$. Portanto, as moradias de baixo padrão de construção, que apresentam muitos locais adequados para abrigar triatomíneos, são as que oferecem maior risco de infecção para seus moradores ${ }^{16}$. Neste estudo, não ocorreu diferença estatística na comparação dos grupos em relação ao tipo de habitação na infância e atualmente, enquanto que o que se refere ao local de moradia houve aumento em números absolutos e relativos de moradores na zona rural.

Com relação ao relato dos indivíduos participantes do estudo de conhecimento e/ou contato com o triatomíneo nota-se que houve predomínio dos que tiveram contato no grupo dos nascidos antes de 1983, ocorrendo diferença estatística entre os grupos. Resultado esperado, após 1983 houve controle do Triatoma infestans. 0 processo de deteccão de triatomíneos com a participação da população significa vigilância contínua, se comparado às atividades rotineiras realizadas, pelas equipes de campo. Na fase de vigilância entomológica a cooperação da população é eficaz. Sensibilizado, o morador se mantém constantemente atento ao surgimento do barbeiro $^{8711}$. Entretanto, a constatação de que neste estudo o grupo de indivíduos nascidos após 1983, apresentou somente um relato de contato ou conhecimento do triatomíneo, torna-se claro a necessidade de buscar mecanismos alternativos, que propiciem efetivamente um grande envolvimento da população na vigilância triatomínica. 0 peridomicilio representa um dos maiores desafios dos programas governamentais, tanto pelas dificuldades na localização e captura de triatomíneos, quanto pela constante recolonização e pelas limitações do uso de inseticidas. Ainda existe o risco de ocupação de áreas trabalhadas pelas ações de controle, por espécie silvestre de triatomíneos, podendo levar a mudanças importantes na epidemiologia da doença de Chagas $^{10}{ }^{18}$. Com a crescente desmobilização do Programa de Controle da Doença de Chagas (PCDCh) no Brasil, a partir de meados da década de 80 , as ações de vigilância e controle tornaram-se menos efetivas, fazendo com que a intradomiciliação dos triatomíneos fosse uma possibilidade concreta ${ }^{21}$. Por este estudo, não se pode afirmar que o triatomíneo foi eliminado, apesar de não terem sido encontrados, quer no domicílio, quer no peridomicílio dos indivíduos estudados e mesmo levando em consideração, que nos anos de 1994 a 1997 tenham ocorrido 40 notificações de triatomíneos da espécie Panstrongylus megistus, não infectados pelo Trypanosoma cruzi $i^{4}$. Portanto, são necessárias futuras e periódicas investigações entomológicas e sorológicas, para se manter avaliação constante da eficácia do PCDCh, no controle da transmissão vetorial da doença de Chagas, principalmente no Estado de São Paulo.

\section{REFERÊNCIAS}

1. Carvalho ME, Latorre MRDO, Ferreira CS, Mello CS, Barata JMS. Soroprevalência de infecção chagásica de Triatoma infestans após medidas de controle. Revista de Saúde Pública 34:15-20, 2000.

2. Carvalho ME, Silva RA, Barata JMS, Domingos MF, Ciarovolo RMC, Zacharias F. Soroepidemiologia da tripanosomíase americana na região do litoral sul, São Paulo. Revista de Saúde Pública 37:49-58, 2003.

3. Coda D, Falci N, Mendes FAT. Contribuição para o estudo e a profilaxia da doença de chagas no estado de São Paulo. Revista do Instituto Adolfo Lutz 18: 83-121, 1958.

4. Coura JR. Doença de Chagas. In: Meira DA (ed) Clínica de doenças tropicais e infecciosas, $1^{\text {a }}$ edição, Interlivros; São Paulo, p.369-377, 1991.

5. Dariush A. Análise do custo - efetividade do programa de controle da doença de Chagas no Brasil: relatório final. Organização Pannamericana da Saúde; 1998. 
6. Dias JCP. Aspectos clínicos, sociais e trabalhistas da doença de Chagas em área endêmica sob controle do estado de Minas Gerais, Brasil. Revista da Sociedade Brasileira de Medicina Tropical 26: 93-99, 1993.

7. Dias JCP. Problemas e possibilidades de participação comunitária no controle das grandes endemias no Brasil. Caderno de Saúde Pública 14 (supl 2): 19-37, 1998.

8. Dias JCP, Dias RB. Participação da comunidade no controle da doença de Chagas. Annales de la Société Belge de Médecine Tropicale 65 (supl 1): 127-135, 1985

9. Diotaiuti L, Faria Filho OF, Carneiro FCF, Dias JCP, Pires HHR, Shofield CJ. Aspectos operacionais do controle do Triatoma brasiliensis. Caderno de Saúde Pública 16 (supl 2): 61-67, 2000.

10. Dujardin JP. Population genetics and the natural history of domestication in triatominae. Memórias do Instituto Oswaldo Cruz 93:34-36, 1998.

11. Falavigna-Guilherme AL, Costa AL, Batista 0, Pavanelli GC, Araújo SM. Atividades educativas para o controle de triatomíneos em área de vigilância epidemiológica do Estado do Paraná, Brasil. Caderno de Saúde Pública 18: 1543-1550, 2002.

12. Goulbaum M. A doença de Chagas no setor industrial. Textos de Apoio: Epidemiologia p. 189-203, 1985.

13. Guhl F, Jaramillo C, Vallejo GA, A-Arroyo FC, Aufderheide A. Chagas disease and human migration. Memórias do Instituto Oswaldo Cruz 95: 553-555, 2000.

14. Leite OF, Alves MJCP, Souza SSL, Mayo RC, Andrade VR, Souza CE, Leite OF, Alves MJCP, Souza SSL, Mayo RC, Andrade VR, Souza CE, Range 0, Oliveira SS, Lima VLC, Rodrigues VLCC, Carvalho ME, Casanova C, Wanderley DMV. Triatomas infestans em área de vigilância entomológica para doença de Chagas, Estado de São Paulo, Brasil. Revista da Sociedade Brasileira de Medicina Tropical 34: 437-443, 2001

15. Lima FO, Silva TL. Distribuição dos triatomíneos no estado de São Paulo. Arquivos de Higiene e Saúde Pública 17: 27-55, 1952.

16. Oliveira-Lima JW, Faria Filho OF, Vieira JBF, Gadelha FV, Oliveira Filho AM. Alterações do peridomicílio e suas implicações para o controle do Triatoma brasiliensis. Caderno de Saúde Pública 16 (supl 2): 75-81, 2000
17. Peñaranda-Carrillo R, Moreira EF, Silveira AC, Leite J, Vinhaes MC, Castro C, Macedo V. Avaliação do impacto das ações de controle vetorial da doença de Chagas, através de inquérito sorológico em Mambaí/Buritinópolis, Goiás. Revista da Sociedade Brasileira de Medicina Tropical 35: 331-338, 2002.

18. Ramos Jr AN, Carvalho DM. Os diferentes significados da certificação conferida ao Brasil como estando livre da doença de Chagas. Caderno de Saúde Pública 17:1403-1412, 2001

19. Schofield CJ, Dias JCP. A cost benefit analysis of Chagas' disease control. Memórias do Instituto Oswaldo Cruz 86:285-295, 1991.

20. Shumunis AG. Trípanosomíase americana: seu impacto nas Américas e perspectivas de controle. In: Dias JCP, Coura R (eds) Clínica e terapêutica da doença de Chagas. Fundação Oswaldo Cruz, Rio de Janeiro, p.11-23, 1997.

21. Silva EOR, Wanderley DVM, Rodrigues VLCC. Triatoma infestans: importância, controle e eliminação da espécie no Estado de São Paulo, Brasil. Revista da Sociedade Brasileira de Medicina Tropical 31:73-88, 1998.

22. Silva RA, Rodrigues VLCC, Carvalho ME, Pauliquévis Jr C. Programa de controle da doença de Chagas no Estado de São Paulo: persistência de alta infestação por triatomíneos em localidades na década de 1990. Caderno de Saúde Pública 19:965-971, 2003.

23. Silveira AC. Situação do controle da transmissão vetorial da doença de Chagas nas Américas. Caderno de Saúde Pública 16:35-42, 2000.

24. Silveira AC, Rezende DF. Epidemiologia e controle da transmissão vetorial da doença de Chagas no Brasil. Revista da Sociedade Brasileira de Medicina Tropical 27: 9-22, 1994

25. Silveira AC, Vinhaes M. Doença de Chagas: aspectos epidemiológicos e de controle. Revista da Sociedade Brasileira de Medicina Tropical 31:15-60, 1998.

26. Vinhaes MC, Dias JCP. Doença de Chagas no Brasil. Caderno de Saúde Pública 16:7-12, 2000.

27. World Health Organization. Control of Chagas' disease. Report a WHO Expert Committee.World Health Organizacion Technical Report Serie 89: 1-95, 1991.

28. Zar JH. Biostatiscal analysis. $3^{\text {rd }}$ edition, New Jersey, Prentice-Hal, Inc. Simon \& Schuster/A Viacom Company, 1996. 